\title{
The Design of Fitness APP for Students Extra-curricular Sports
}

\author{
Bao-xin HUANG \\ Department of Sports, Northwest University, Xi'an 710069, China \\ huangbxapp@163.com
}

\begin{abstract}
Keywords: students; fitness app; extra-curricular sports; model design
\end{abstract}
\begin{abstract}
Fitness apps have swept the whole society and have had a profound effect on people's exercise behavior. The sports apps promoted people's exercise behavior and habits significantly. Fitness APP into a new trend on college campuses, it can exercise anytime, anywhere, on-demand occurs and also life-long fitness. Through the good experience of fitness app and interactive perspective, elaborate design and based on needs analysis and basic principles of the possible model designed to discuss the content, intended departure from the students' bodybuilder needs to optimize fitness APP is designed to improve the current shortcomings of the fitness of APP, it is part of the construction of a simple model to try, for research reference.
\end{abstract}

\section{Introduction}

Extracurricular sports refer to the physical education activities that student conduct in their spare time. Students use various physical exercises and methods, to achieve physical development, enhance physical fitness, improve sports skills and enrich the cultural life of leisure[1]. Extracurricular physical exercise is one of the important ways to achieve the goal of school physical education. It is an indispensable organization form of school sports. However, many studies indicates that many students do not take the school's extracurricular exercise system seriously. Instead, they are busy with their own work in extracurricular exercise time. In case of that, there is no real effective exercise[2].

In recent years, researches on School Physical Education under the information environment have become quite popular. With the rapid development of mobile Internet, the application of 4G mobile communications technology and data technology as the core of the network technologies, helps more advanced technology play a breakthrough role in the field of school sports. Smart phones are becoming more and more popular in modern college students, and the fitness software in the smart phone has become an important tool for their physical exercise. The function of fitness software in the smart phone is simple, free, powerful, and it has great application prospects in the college students' Extracurricular fitness. At present, there are a variety of fitness app markets. However, the widespread content is boring, the logical is confused, the production is rough and also some other shortcomings. the reason is not really from the perspective of users and fitness to design and research[3]. In order to solve these problems, based on the analysis of College Students' physical fitness app demand, this article attempts to embark from the perspective of fitness and further exercise of APP structure model and function module design, in the hope of realizing the optimization of extracurricular fitness app.

Design concept. The operation of logic, interface interaction, user experience and other aspects of the design needs to be taken into consideration. However, for users, the most intuitive feeling is UI APP, the most useful is the interface interaction. After all, media interface interaction level directly affects the athletes' exercise motivation and enthusiasm, thereby affecting the app and the effect of exercise; and for the designers, interaction level reflects the concept and advantages of the interface best, which indicates the designer's thinking and visible interface design function. So in order to realize the optimization of extracurricular sports fitness app, the most fundamental way is to achieve reasonable and reliable interactive interface, to meet the real needs of users. Firstly, the interface's sense of understanding should be enhanced, so that users can feel APP even if the delay occurs and also enhance the user's sense of trust and use. Second is to optimize the UI element. UI is the user's most 
intuitive and strong sense of the overall APP and a user-friendly UI is often more attractive to attract users. Third, attention should be paid to the app sharing, all the user'd information and usage can be saved through just one account whether it is in the smart phone or tablet, reducing the user's inconvenience of information processing. Fourth, the application of technical advice should be taken into consideration. Persuasive technology is the design of user intent. The user behaviors and activities are accurately observed through the sensor and detection technique of smart mobile devices. After obtaining a mass of users physiological data index in the intelligent equipment, reasonable and effective information should be conveyed to the users in appropriate time, to guide the user's appropriate behaviors, alert and help improve the unhealthy way of life to achieve the goal of persuasion.

Model construction. Abstractly, different from three elements in traditional tutoring research "teachers, students, motion" , the app is based on "sports fitness, fitness community, app server of learning", to realise the three pairwise two-way interaction. Besides, the exercise and fitness community is the core of the whole exercise, playing a user role, and app learning server is to provide a variety of services to users, and users will be the use of feedback information to the server. The app will continue to optimize and upgrade, offering mutual benefit. Therefore, we need to focus on a new way of thinking and perspective, as shown in Figure 1.

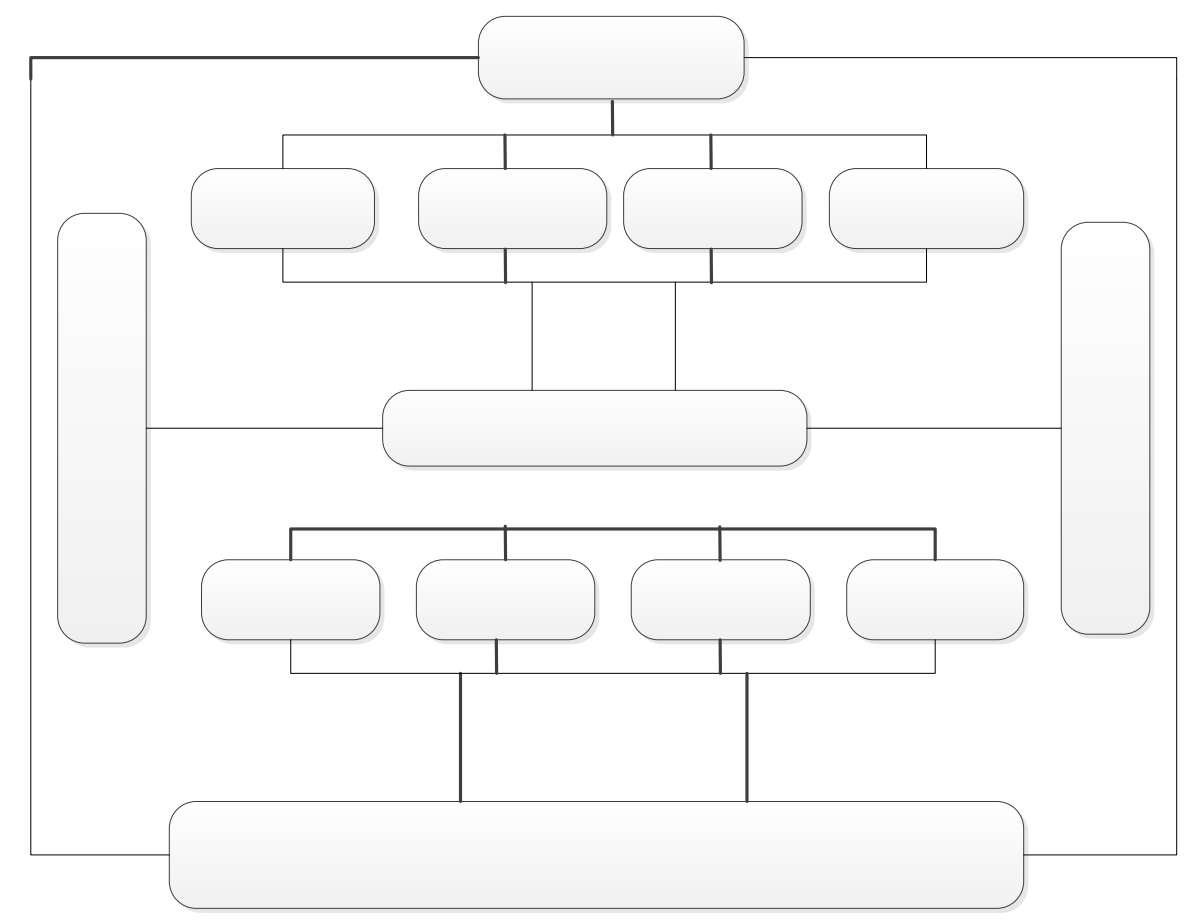

Fig. 1 The elements of fitness APP model

Overall, the structure of the APP consists of three parts: "the bodybuilder", "the community" and "the fitness server". " the bodybuilder" and "the community" are the users, "the fitness server" is to provide a variety of services to users. At the same time, fitness app server is composed of data, interactive, training, system evaluation and so on. Data center is used to store the latest fitness information and some of the auxiliary fitness data, so it is a huge data base. Fitness center is a link, which connects the fitness center with each other. The fitness center can interact and communicate with the body building community through interaction center. Personal center is a platform to help users manage their personal information. Health evaluation consists of two parts: self assessment and evaluation of teachers, so that students can evaluate the fitness results timely and accurately, effectively test their fitness results, significantly enhance the users' confidence in bodybuilding and their learning effect.

Module design. The fitness app structure model is shown in Figure 2. The fitness app is composed of seven modules, namely "fitness service, experience, interaction, motion records, information, announcement and test". Module service can provide personalized settings, such as head, nicknames, 
etc., to increase the students' interest, and "experience, interaction and motion record" three big modules must be used to improve the fitness effect. "information, announcement and test" module provides personalized fitness guide, which can, for example, import fitness goals, access to information of fitness and evaluate fitness effect and information feedback of the modules from the" information and announcement" . Therefore, the module has a unique function, but also with the rest of the other linked to a common role in the fitness APP.

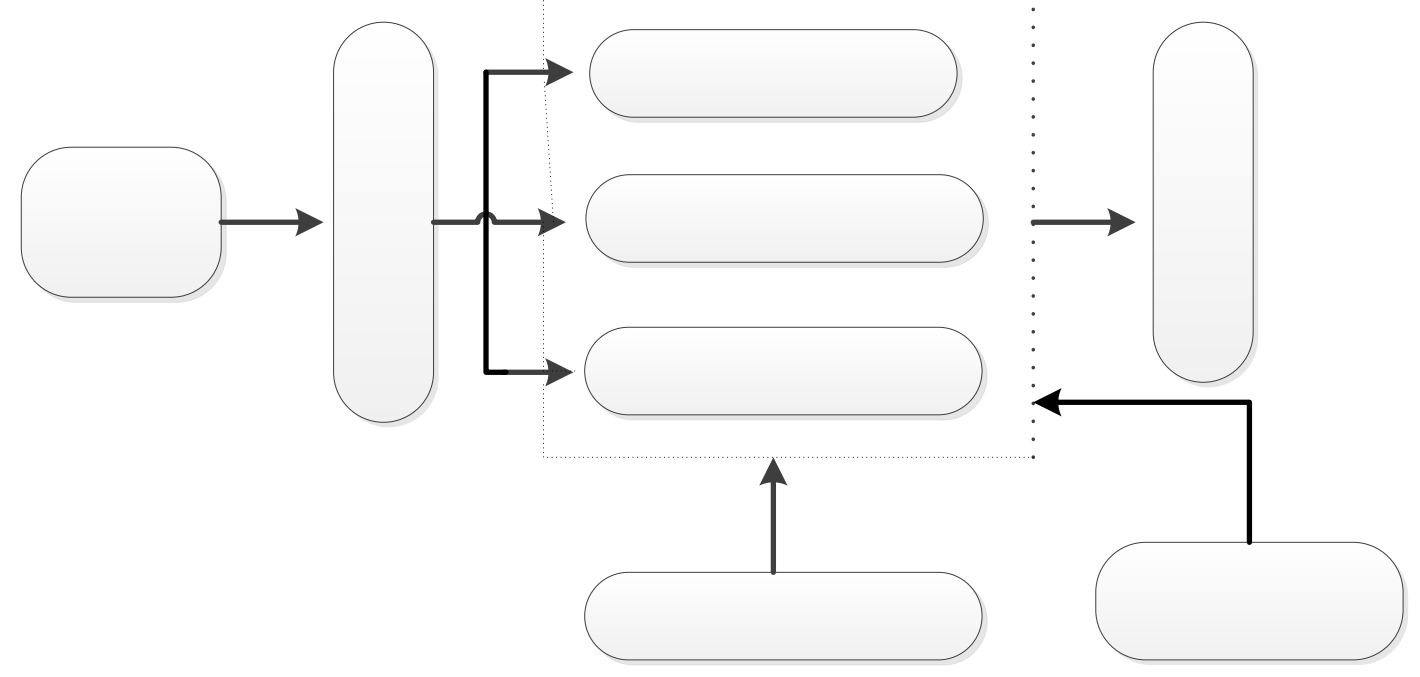

Fig. 2 The model of fitness APP

The relationship between the seven modules in Fitness APP is inseparable and their respective unique functions complement each other, constituting a complete fitness APP ecosystem. According to their own conditions and needs, bodybuilders can choose module for personalized content, while the entire functional module design is complete, such as Figure 3.
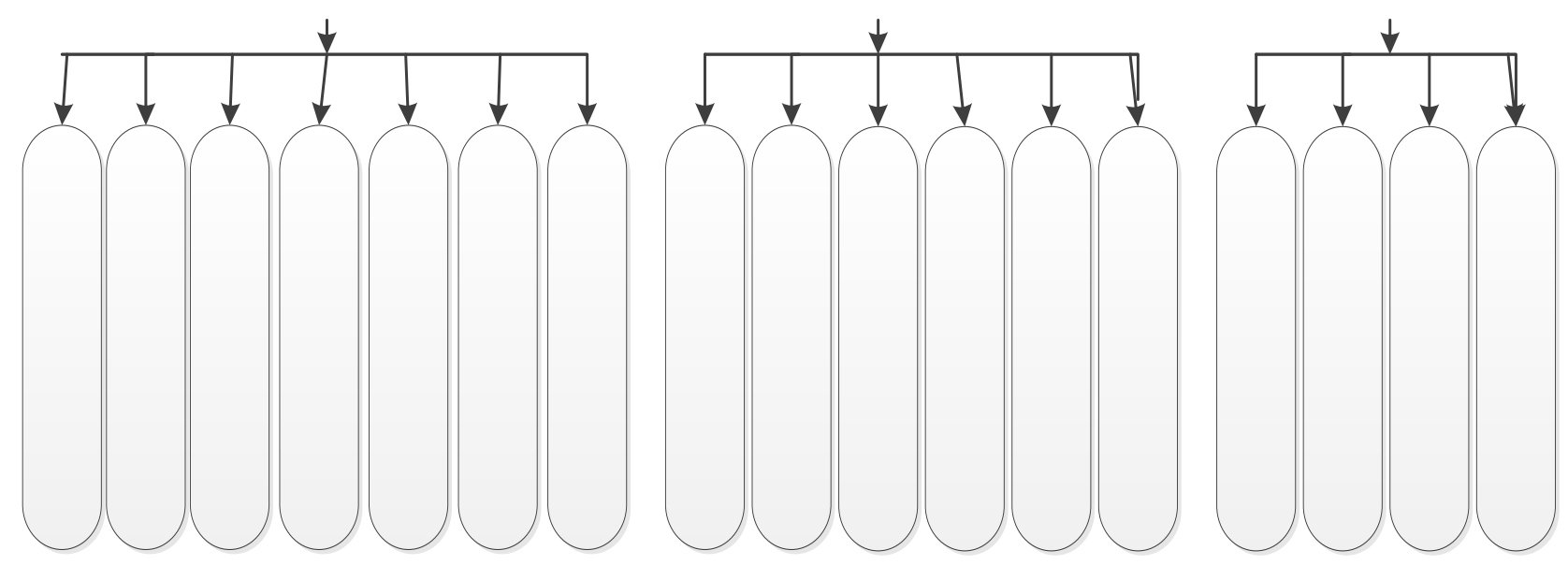

Fig. 3 The functional module of fitness APP

\section{Summary}

Mobile fitness software application in the college students' extracurricular physical exercise can not only provide a scientific guidance to students' Extracurricular fitness, but also help schools to accurately determine whether students participate in physical exercise attentively, urging the effect of college sports. Also, it can help schools in the management of efficiency and the effect for students' Extracurricular Physical exercise. Besides, it is conducive to the actual situation of the analysis of College Students' physical exercise, providing basis for a more specified reasonable extracurricular exercise system.

\section{References}


[1] Ping Liang, College sports and health curriculum, China Electric Power Press, first ed. Beijing, 2009.

[2] YANG Pei-ji, ZHOU Xue-bing, YU Xiao-dong, A Research on the Current Situation of University Stuendts' Activity after School in Parts of China, Journal of Beijing Sport University. 32(2009)91-93.

[3] WU Ruo xi, WANG Qing jun, Fitness APP: development status, problems and countermeasures, Journal of Shandong Sport University. 31(2015)18-22. 